Visualizing Objects, Places, and Spaces: A Digital Project Handbook

\title{
"The Brontë Cabinet": A \\ Virtual Gallery
}

\section{Catherine J. Golden}

Published on: Mar 02, 2021

DOI: $10.21428 / 51$ bee781.4b5a3255

License: Creative Commons Attribution-NonCommercial 4.0 International License (CC-BYNC 4.0). 


\section{Author \& Project Role}

Author: Catherine J. Golden, Professor of English and the Tisch Chair in Arts and Letters, Skidmore College

Role: Instructor

\section{Assignment URL \& Files}

\section{Assignment handouts:}

Assignments for Digital Handbook. pdf

$870 \mathrm{~KB}$

Assignments URL: $\underline{\text { htps://editions.covecollective.org/content/bront\%C3\%AB-cabinet }}$

\section{Learning Objectives}

What did you want students to be able to do by completing this assignment?

Students learned by completing the following tasks:

- Assembling a group of related objects that the Brontës created, lived with, and/or incorporated into their writing.

- Deepening engagement with the Brontës' lives and the Victorian era by designing a virtual gallery "case."

- Identifying each object's significance, noting the date, title, artist, location, and any other relevant information.

- Formulating captions to explain the meaning of each object and how the objects in a case work together to strengthen our understanding of the Brontë sisters' lives and legacy. 


\section{Technology-Dependent Learning Outcomes}

Was there anything this assignment taught students that you felt they wouldn't have been able to learn through other types of class assignments?

The assignment is designed for student use on the Collaborative Organization for Virtual Education (or COVE).

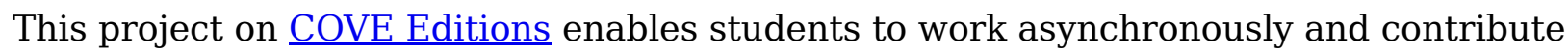
to a unified class gallery without meeting in person. I turned to COVE because of the pandemic, and the learning objectives could not have been achieved without this platform. But the technology is valuable for teaching after the pandemic as well. Different from a brick-and-mortar exhibition designed to fill four display cases, each class member on COVE can design a case individually and thus play a greater role in the exhibition. Students gain knowledge through independent research and working with suggested resources including The Victorian Web and The British Library. websites. However, this assignment could also be designed with material objects from a college archive that can be photographed for virtual display.

Ideal for the "flipped classroom" approach, students work independently on finding objects and researching and writing captions for their own cases before coming to class for face-to-face discussion with peers in student-run breakout rooms that facilitate the "flipped" classroom model as well. The platform also facilitates collaboration; each student creates a thread on the class gallery, rather than post an entry for an individual exhibit; thus, the platform promotes a shared collective. COVE also allows for the creation of a permanent public web address to extend the life of the exhibition beyond the constraints of a single semester.

\section{Skill Level}

What is the course title and level?

This class, "EN 229: The Brontës," is an intermediate level English literature class that enrolls first-year students to seniors. We adopt new historicist, gender studies, and material culture studies approaches to study the Brontës, arguably the greatest English literary family of the nineteenth century. Readings include Charlotte Brontë's Jane Eyre (1847), Emily Brontë's Wuthering Heights (1847), and Anne Brontë's The Tenant of Wildfell Hall (1848) as well as biography and poetry by the three sisters and 
their brother, Branwell. In addition to writing papers and giving oral reports accompanied by PowerPoints, we annotate Jane Eyre on COVE Studio and design an exhibition of objects to illuminate the Brontës on COVE Editions.

What kinds of prior knowledge are necessary to complete this assignment? How do students gain this knowledge?

Students do not need to be well-versed in the Victorian Age to complete the "Brontë Cabinet" assignment, but they do need to be well-read in the Brontës' literature and various literary critical/cultural theories. They gain this knowledge by taking the course. Students also gain insight by researching independently and working with suggested resources including $\underline{\text { The Victorian } W e b}$ and The British Library websites.

Once students get a subscription on COVE (the cost is $\$ 10$ per year), there are set steps required to become a member of a particular class on COVE as well as to create a thread for a gallery case. The COVE Collective provides tutorials to help students sign on and navigate the platform. There is no prior knowledge necessary to use COVE, just a willingness to get involved in a virtual project. Students gain knowledge and skills through practice. Breakout rooms provide students a space to help one another gain comfort with the platform and give feedback to each other on their cases. Some trial and error is involved; for example, the images must be a particular size to be uploaded, so students often face challenges that can be addressed during class or in breakout rooms.

\section{Assignment Description}

Beloved pets and places the sisters visited as well as material objects that the sisters lived with and incorporated into their writing help us to set the Brontës in their cultural moment and to understand each sister better. In The Brontë Cabinet: Three Lives in Nine Objects (2015), Deborah Lutz investigates personal objects and pets owned by the Brontë sisters to illuminate their Victorian owners. Students, in turn, construct their own Brontë cabinet on COVE. Each student chooses 2-4 objects that work together to convey a meaningful narrative about an aspect of the sisters' lives; for example, the contents of Charlotte's writing desk along with that desk itself tell us about the uses of a writing desk and the interests and accomplishments of its owner. Each student creates an introduction to their case and writes captions with headers to label the items and explain how they work together to display an aspect of the Brontës' 
lives and their literary legacy. The cases cumulatively create a rich and varied virtual class gallery.

\section{EXHIBIT:}

\section{The Brontë Cabinet}

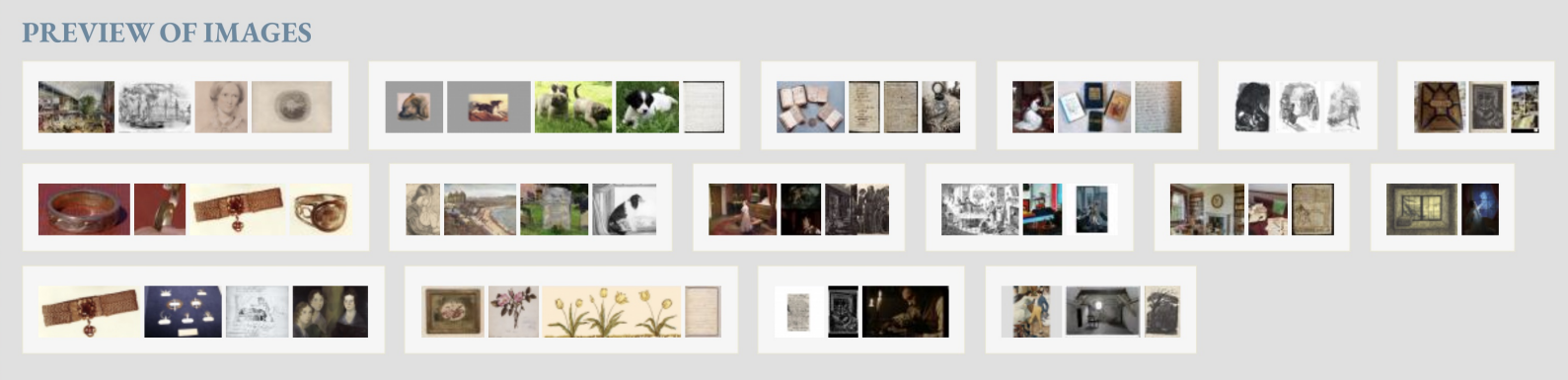

COVE gallery of cases for "The Brontë Cabinet."

\section{Emily Brontë's Writing Desk}

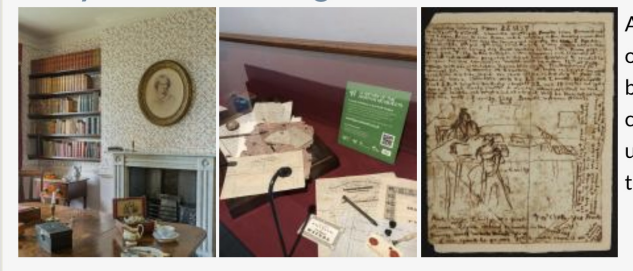

Also known as the lap desk, writing slope, writing box, or writing cabinet, the portable writing desk originated in the 17th century, intended to carry everything necessary for a man's correspondence yet be small enough to carry with him on his horse. The interior of the Victorian version is sloped and covered in a fabric, like leather (for men) or velvet (for women), with surfaces that lift up, revealing space underneath for writing supplies. The back of the desk has compartments for writing utensils, curved so that they could be easily removed and replaced. The walls of these...

\section{Victorian Letter Writing in Brontëan Novels}

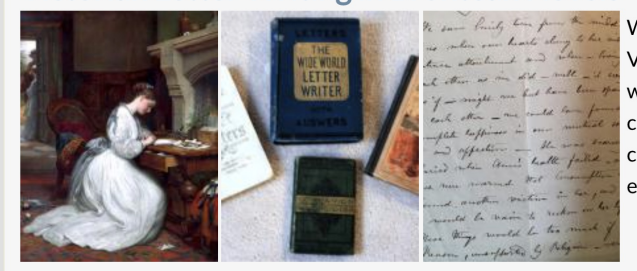

With the revolution provided by the Penny Post in 1840 , letter writing became a crucial aspect of Victorian life. It allowed for people to remain in contact over long distances and long stretches of time without having to travel very far to see them in person. The Brontës, isolated in Haworth and largely contained within their home, utilized letter writing as one of the sole avenues available to them to contact the outside world, and letter writing's importance in both their daily lives and in the Victorian era as a whole is reflected in their novels, all of which feature letter writing to...

\section{Miniature Books by the Brontës}

As children, the Brontës were very creatively driven. Because they lived in relative
isolation from other children, they were close and invented entire worlds of their
own with stories filled with colorful characters. Branwell and Charlotte created a
land called Angria inhabited by dukes, princes, and kings. Emily and Anne, feeling
excluded from the close relationship that their older silbings formed over their
creation of Angria, broke off from their older siblings' world and created their own
island of Gondal. This second world was also complete with the tales of its ruler,
King Julius,...

Cases 2-4: Three approaches to the material culture of writing from "The Brontë Cabinet." 


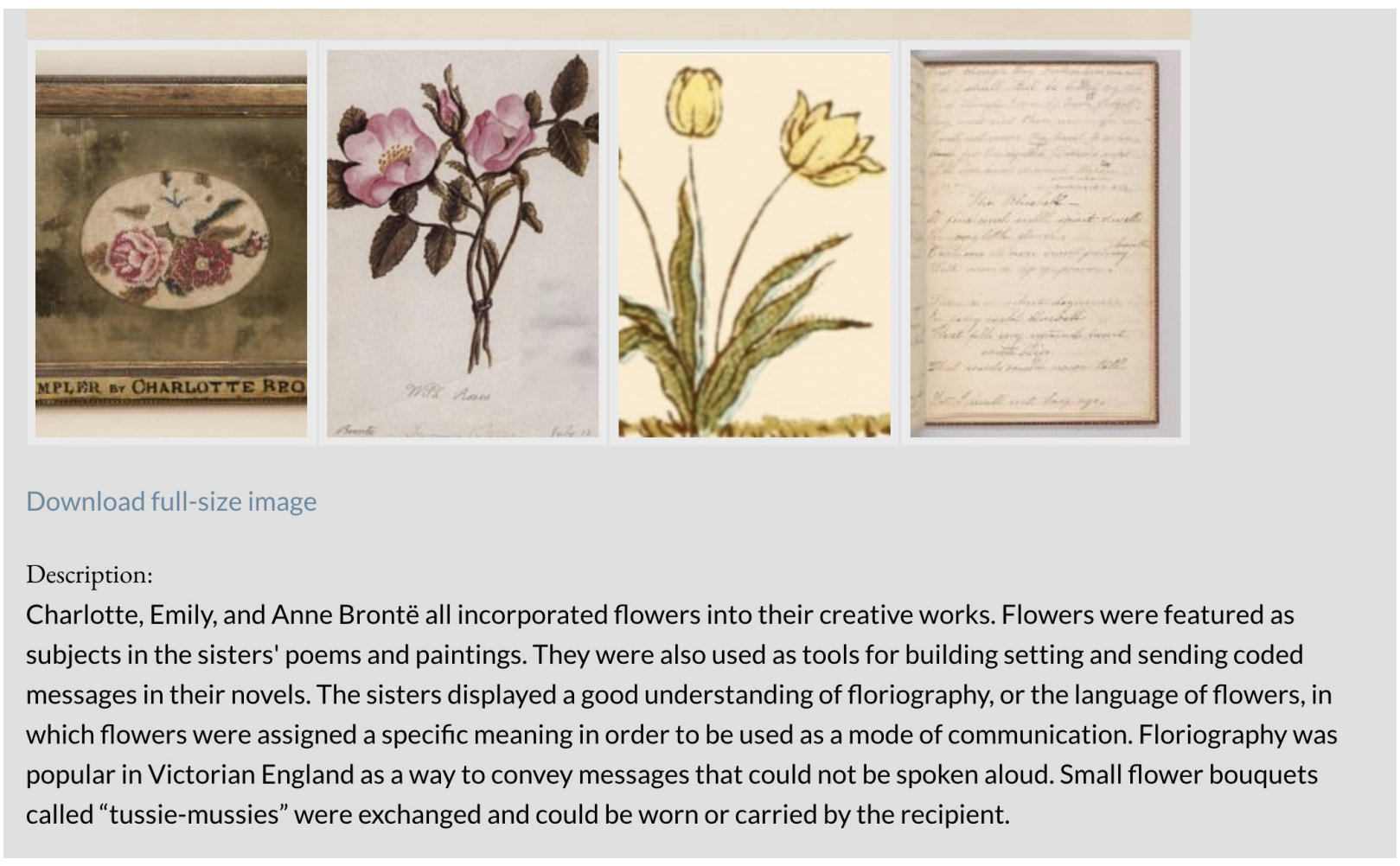

Case 7: "Flowers in the Brontës' Works"-floriography in needlepoint, painting, and literature in the work of Charlotte, Emily, and Anne Bronte.

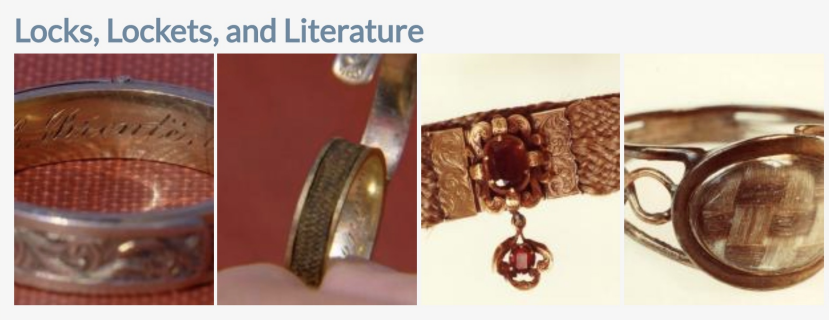

March during the year 1855 , it can...
Charlotte Brontë's Hair Ring, March 1855, Wales.

The first two images in this case show a ring with Charlotte Brontë's hair within. Inscribed in the ring is "Brontë, March 1855." According to a 2019 article in The Guardian by Alison Flood, the ring was found in an attic in Wales. The owner of the ring is unknown, but speculated to belong to Arthur Bell Nichols following Charlotte's death. Mr. Nichols would have worn the ring with Charlotte's hair as a way to stay connected with his wife past the grave. As Charlotte passed away in

Case 8: "Locks, Lockets, and Literature"-hair jewelry and locks of hair in the life and fiction of Charlotte and Emily Brontë. 

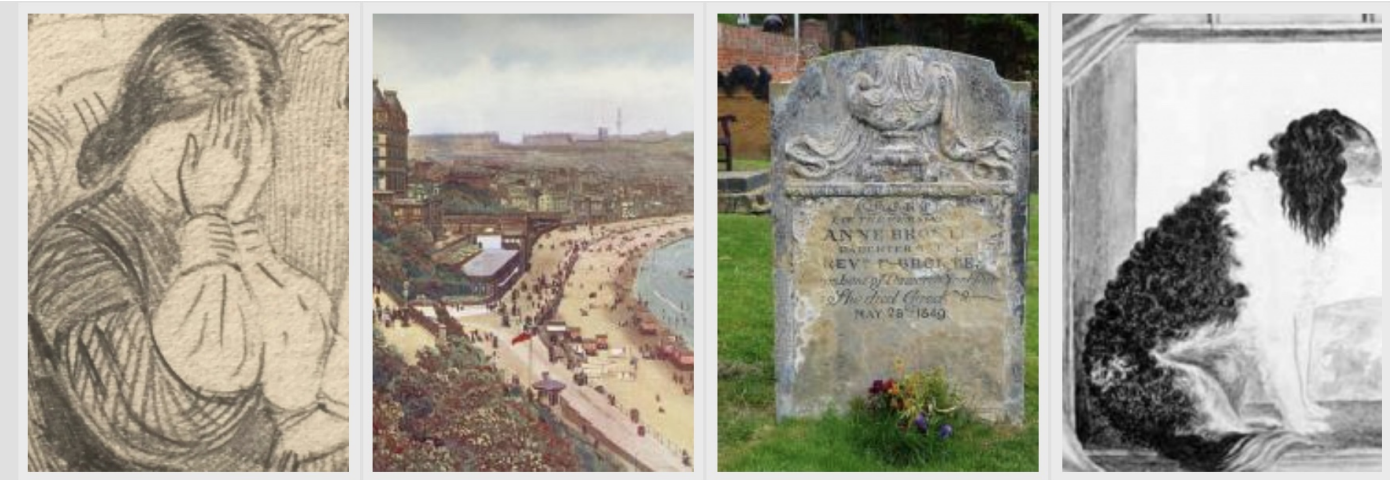

Download full-size image

Description:

During the Victorian era, beaches and mourning were inevitably connected. With consumption taking loved ones from families, people including the Brontës would bring their sick to beaches in hopes the fresh salty air would heal them. Scarborough Beach was one of these places. Anne Brontë had many happy memories at Scarborough Beach from when she traveled there as a governess to the Robinson family of Thorp Green Hall, annually spending about five weeks there per trip. When Anne was dying of consumption, her sister Charlotte and friend Ellen Nussey brought her to Scarborough Beach in attempt to heal her and ease her pain. Anne Brontë died there one May 28, 1849 and was buried there in St. Mary's churchyard overlooking the beach she once cherished so dearly.

Case 9: "The Brontës, Mourning, and Beaches"-an examination of Scarborough Beach in the life and death of Anne Brontë.

Supernatural \& Imprisonment: The Red Room

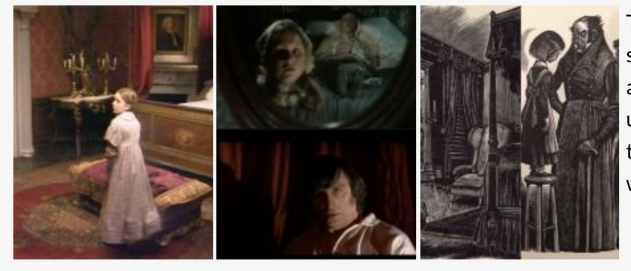

The Red Room is one of the first climactic scenes of Jane Eyre. This series will be addressing the supernaturalness and imprisonment of young Jane during a moment in her life where she was unhappy and mistreated by both her aunt, Mrs. Reed, and children. The red-room is significant to how Jane understands herself and becomes a recurring motif throughout the novel, in which Jane must bear the trauma of the red-room and learn to overcome the eeriness and abuse as she grows into an independent woman. Through BBC series adaptations and Fritz Eichenberg's illustrations, the case...

Case 11: "Supernatural \& Imprisonment: The Red Room"-a multimedia analysis of the iconic Red Room of Charlotte Brontë's Jane Eyre.

\section{Time Needed}

How much time did you allot to this project?

I formally introduced this assignment in the final third of the semester (although I referred to it from the first classes to encourage students to begin to think about it). Students were expected to gather source material and choose a narrative thread for their cases as homework during weeks nine through ten of the thirteen-week semester; during weeks eleven and twelve, I also gave direction as needed on finding 
materials to fill gaps in their story arcs. For weeks nine through twelve, students worked on the cases asynchronously as homework. During this time, students met in breakout rooms on Zoom to discuss their cases and to troubleshoot issues, such as how to reformat images for successful uploading and how to arrange items in a virtual case to the best effect. Following breakout room sessions and full class discussions, students independently edited their captions and headers for grammaticality and clarity. We devoted the final week of classes (week thirteen) to student presentations of the cases (10-minute presentations followed by questions and comments). Here students took full ownership of the assignment. Since the gallery was not due until after classes ended, students were granted time to make final changes in response to questions and comments they received from their peers and professor. Once the gallery was complete, I shared the link with interested faculty and students and the editors of COVE to expand the audience for the virtual gallery.

\section{Support \& Training}

What kinds of support or training did you provide to help students learn to use new techniques or specialized tools?

I introduced students to COVE and the tutorials on the website. After gaining comfort with the COVE site and tools, students chose objects, found source materials in the public domain, and arrived at their own narrative thread. As needed, students reviewed class handouts and COVE tutorials, consulted with their peers and me, and revised their cases for content, visual appeal, and grammaticality.

I also designed a case as a loose model for students to follow. During a class meeting, I shared my screen on Zoom to allow students to watch me upload images and write captions. In addition, I suggested websites students could browse to collect source material in the public domain and met with students to help them download and arrange their chosen images and revise their labels and captions. During class, I introduced the students to two websites that contain an extensive collection of texts and images of the Victorian age- The Victorian Web and The British Library websites. I directed the students to pages that explain the nature of each site for the purposes of education and scholarship. While all material in The Victorian Web can be reproduced for educational and scholarly projects, The British Library includes "Usage Terms" for all material on the website; if the material is marked "public domain," it can be 
incorporated into their display. I also reviewed key words students can use to search for images and texts on these sites.

For example, using the search function on The Victorian Web, students and I looked for the Brontës' names, important works (e.g. Jane Eyre), and Victorian objects that the Brontës used (e.g. writing desks) to generate a list of potential objects to include in a virtual display case. In addition, I introduced the students to college resources, including the Norman M. Fox Collection at Skidmore College, which spans the 15th to the 20th centuries with a significant holding of Victorian illustrated books. Prior to the pandemic, I took students to the rare book room to examine these illustrated books which they could use for brick-and-mortar exhibitions. Fortunately, the Fox Collection is digitized and so readily accessible for virtual display.

Did you need any specialized equipment, tools, or human resources to make this assignment feasible? If so, please describe.

As described on its website, COVE is "a scholar-driven open-access platform that publishes both peer-reviewed material and 'flipped classroom' student projects built with our online tools. It is maintained by a number of field groups and independent

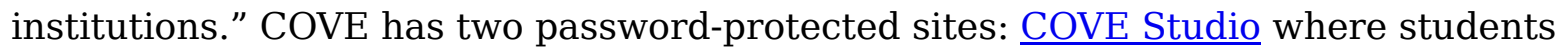
can read and annotate pre-formatted vetted primary material; COVE Editions, which publishes scholarly editions and "flipped classroom" projects using COVE tools, which include a gallery-builder, a map-builder, and a timeline-builder.

The only requirement is a membership to COVE, which can be attained through a COVE-only membership in the North American Victorian Studies Association (NAVSA). Students and professors alike are charged a \$10 fee for use of these tools. The platform is easy to navigate and includes tutorials on how to design exhibitions, create maps and timelines, and annotate pre-formatted and vetted works housed on COVE Studio. Students and I received prompt, helpful, and reassuring feedback from the COVE editors if any problem arose.

\section{Assessment}

How did you assess or grade this project?

I designed a rubric to assess this project, which I made available to students at the start of the project. In addition, students received feedback from professor and peers 
at multiple stages of the assignment.

The rubric covers the visual, oral, and written literacy skills to be evaluated to help students to gauge their progress with the assignment and to understand how their final work will be evaluated. Criteria include

- the design of a narrative for the case,

- selection of objects,

- clear labeling and visual arrangement of objects,

- clarity and grammaticality of written content, and

- oral literacy skills for the class presentation.

Critiquing occurred during weeks nine through twelve in breakout rooms and large group meetings where we discussed the cases in progress. These group meetings served as a "draft" phase for the project and helped to establish a sense of shared commitment to the design of a virtual gallery. The final classes were student-led and generated lively discussion. Following these presentations, students incorporated feedback from their peers and me to make final changes to their cases.

\section{Challenges \& Opportunities}

If you assigned this project again, would you change anything? If so, what?

I presented this assignment as an outgrowth of the work of Deborah Lutz, but for the next incarnation I also plan to assign the preface to her book entitled "The Private Lives of Objects" to give students a clear explanation of material culture studies as a tool to recover history and the life of an object's owner. To improve the project, I plan to develop a workflow with due dates to help students think through the requirements for each stage of the project and to work in a timely manner. I was surprised that a number of students were reluctant to post their material as they progressed through the project, electing to work privately on a Google Doc and then post a completed case. The workflow with due dates for posting work in progress will give students a clear time frame for their asynchronous work and promote the "flipped classroom" approach in the classroom-students will have work to bring to the breakout rooms at regular intervals. Accordingly, I will incorporate this criterion into my assessment rubric. 
Describe any trouble spots or complications someone else might want to be aware of before trying a similar assignment in a course of their own.

Students had some difficulty joining COVE, so a careful explanation of the steps to do so is helpful. A new video created by the COVE editors will prove useful for students signing onto and getting comfortable with COVE. Moreover, the editors of COVE offer excellent support to professors and students to help navigate the tools, so taking advantage of those opportunities is important. Some students had trouble understanding that they needed to create a thread on our class exhibition rather than design an individual entry. Some students thus had to do an extra step of moving material from an individual thread to the group exhibition, which was a timeconsuming process. Moreover, some students needed a lot of help in gaining comfort with the platform.

Modeling and sharing my screen to show students how to start a thread as part of a class exhibition was helpful, but some students still had trouble working independently. To help these learners, I created a handout of tips for designing a gallery on COVE that addresses the concerns that arose in class discussion, breakout rooms, and the Zoom chat. The handout, which students can use for further guidance, includes screen shots to illustrate the necessary steps for adding images and captions. Other students had challenges uploading images. On COVE, images can be uploaded in a range of formats (png, gif, jpg, and jpeg), but they need to be less than $20 \mathrm{MB}$ but larger than 640x480 pixels. Some images that students wanted to upload did not fall within these parameters, so I instructed them to resize images in Photoshop to upload them successfully. By providing ample resources and assigning tutorials on COVE, instructors can help students to gain comfort with the platform, avoid extra steps, and build an engaging virtual gallery case with ease.

Banner Image: Portrait of the Brontë Sisters by Branwell Brontë, 1834. National Portrait Gallery. Image from Wikimedia Commons. 